\title{
OLGA ZAMBONI
}

\section{SGLEDADES}

\section{(KEFLFXIONES EN TORNO A DIDO Y ENEAS, ARQUETIPOS HUMANOS)}

\author{
“...porque en el fondo, y justamente en las cosas \\ más profundas y más importantes, estamos inde- \\ ciblemente solos".
}

R. M. RILKE

\section{SERES CONTINGENTES}

Se ha dicho que el primer tercio de la Eneida es una auténtica tragedia de amor. Y Dido, esa perfecta criatura virgiliana, la gran agonista. Orgullosa impotencia frente a fuerzas que no comprende; desamparo humano asumido con valor; reacción apasionada que la acerca fraternalmente a otras figura femenina trágica: la Medea de Eurípides, que tampoco conoció la $\sigma \omega \varphi p o \sigma u ́ v n$

Aún a riesgo de repetir lo muchc que se ha escrito sobre el tema, seguiremos los trazos con que el poeta la caracteriza, frente a los del héroe que la enamora y la abandona. Vidas intensa aunque circunstancialmente unidas en un momento de su transcurso. Se trata de seres, dice Teodoro Haecker (1), imposibilitados de marchar juntos en el orden de la naturaleza porque no han sido destinados el uno para el otro en el orden del espíritu. De ahi el sufrimiento y las lágrimas, las quejas al cielo por lo incomprensible de ese sino trágico. Punto de partida de nuestras reflexiones han sido este pensamiento y el juicio de Ettore Paratore que, a propósito del episo. dio de Dido y Eneas, dice:

“...contraste entre el querer del Hado y el sentimiento de almas dolorosamente ligadas a su contingencia".(2)

Esas almas son territorio de luchas frente a un entramado de fuerzas extrañas que domina los pasos y el acontecer de la Historia. Y aunque uno solo es el resultado posible (o no habría habido Eneida), queda a salvo el juego de las pasiones liberado al arbitrio humano. Mano maestra de Virgilio en la descripción psicológica de situaciones, deliberaciones de conciencia, reac- 
ciones. Nos espeja a todos 108 humanos en esos seres contingentes, carne de sombra y reflejos. En la soledad última e íntima de cada uno; es ese "misterio ante el cual él se inclina, pero con una tristeza que busca en vano la explicación", como señala Guillemin refiriéndose a la tragedia de la guerra y a la muerte de los jóvenes (3). Raíz de eso que se ha dado en lamar la "melancolía virgiliana", su reiterada preferencia por los contraluces, por las "zonas de penumbras".

\section{DIDO Y ENEAS}

Cuando Eneas llega a Cartago, ya es conocido en la ciudad. Murales palaciegos reproducen las desventuras de Troya (lacrimae rerum) y el caudillo se contempla a sí mismo con honda pena: (4) se quoque principibus permixtum agnouit Achivis, $(I, 488)$ Dido es entonces la mujer fuerte: dux femin a facti en las palabras de Venus cuando se le aparece a su hijo bajo la forma de una virgen espartana; le informa en la ocasión de la historia del lugar y de sus habitantes: la peregrinación de los tirios, sus azares hasta asentarse en las costas norafricanas donde están en ese momento levantando su nueva ciudad:

\section{... Longa est iniuria, longae}

ambages; sed summa sequar fastigia rerum. (I, 341)

A través de esos "summa fastigia", resumidores de los hechos que llevaron a Dido a ese sitio se entreve una época -anterior a la iniuria- díferente: la reina sidonia unida "bajo felices auspicios" a Siqueo, a quien su padre se la habia entregado virgen. Un matrimonio concertado al modo tradicional que no descarta empero la felicidad conyugal y el gran amor que aquélla profesaba a su marido:

...et magno miserae dilectus amore, $(I, 344)$.

Epocas en que ella acató con sumisión la norma. Puesta luego en una situación límite con la traición de Pigmalión, hermano suyo y asesino de su propio cuñado, sabe vencerse y dar pruebas de fortaleza verdaderamente viril. (Una probable etimologia señala que Dido, en fenicio, significaria "mujer decidida").

Pero esa fidelidad al esposo muerto, esa negativa sistemática a contraer un nuevo enlace (aún a despecho de ventajas materiales y de estado) es una especie de coraza, protectora de su ser más profundo, de su personal interioridad.

Ha asumido la solitudo imperii con una alegría que es, en realidad, firmitas animi. El calificativo laeta le es reiteradamente atribuido:

Talis erat Dido, talem se laeta ferebat (I, 503). Eneas, al dirigirse a ella por primera vez, agradecido por la hospitalidad que le ofrece, le dice exaltándola:

sacuila?

Quase te tam laeta tulerunt 
(Como si se hubiera reconocido, destinos paralelos en el dolor, en las grandes responsabilidades $y$ en el renunciamiento, la invoca: 0 sola... miserata... unica capaz de apiadarse, por haber sufrido vicisitudes semejantes a las suyas: la pérdidade su centro,la familia, la casa, la ciudad. Respuesta piadosa la de Dido en estas circunstancias: Non ignara mali miseris succurrere disco, $(I, 630)$.

Hay un signo alegre, casi de plenitud, en esa Dido regina: aunque solitudo, es laeta -y pronto será turbada- porque ha cumplido con el destino de conductora de su pueblo, mientras Eneas está marchando rumbo al suyo, playas todavia lejanas.

La ciudad de Dido tiene murallas y torres ya palpables;la prometida a Eneas apenas ofrece la consistencia de los sueños.

En el orden de la naturaleza, todo parece unirlos. Ambos son jóvenes y bellos: Regina...forma pulcherrima Dido, (I, 496).

Solemne su porte, riquísimos sus atributos regales. Virgilio la compara con Diana, acaso por esa condición casi masculina de la reina de las amazonas, que gobierna enérgica sus silvestres feudos e imparte justicia por sus propias manos, sin apoyo ni compañía de varón. Dido ejerce con dignidad sus poderes politicos, decide y dispone; es respetada por su pueblo. Su condición de univira, además, ha elevado su fama a los astros.

Qualis...

exercet Diana choros,...

$(I, 498)$

...instans operi regnisque futuris. (I, 504)

saepta armis solioque alte subnixa resedit.

Iura dabat legesque uiris, operumque laborem

partibus aequabat iustis aut sorte trahebat: (I, 506)

Eneas, por su parte, al aparecer frente a la gente cartaginesa, luce un aura divina, infundida por su madre Venus, quien ha soplado en su mirada "laetos honores" $y$, en su apostura, la luz de la juventud:

Restitit Aeneas, claraque in luce refulsit os umerosque deo similis;...

Posteriormente, ya en el instante previo a la partida de caza, el poeta lo comparará con Apolo, el dios rubio eternamente joven (y también desdichado en amores):

...Ipse ante alios pulcherrimus omnis

infert se socium Aeneas atgue agmina iungit

Qualis ubi hibernam Lyciam Xanthique fluenta

deserit ac Delum maternam inuisit Apollo

... tantum egregio decus enitet ore. 
Ambos son nobles e inteligentes. La pérdida del compañero (Siqueo y Creusa) y de la patria los ha madurado en la experiencia del dolor. Ambos están en idéntico trance de fundador (conditor gentium); pero, como ya dijimos, Dido tiene el sitio; Eneas en cambio lo busca. $Y$ aunque conoce algunas señales que se le darán cuando llegue a la tierra elegida, por un momento da cabida en su pecho a la tentación de detenerse en Cartago. Se abandona a sí mismo en esa ilusión, frecuente refugio del troyano: es hombre más bien contemplativo, no impelido en una primera instancia a la acción, y con tendencia al desánimo. Sin embargo, lleva a cabo su misión, a pesar de sus flaquezas, por lo que su mérito se acrecienta y en forma paralela, su humanidad.

Ambos son meros instrumentos del Fatum, si bien en este aspecto debemos señalar divergencias: Venus jamás abandona a su hijo, vela por él, es su presencia providencial. Dido en cambio está protegida por Juno sólo esporádicamente. Miás bien es objeto que una vez usado se abandona o se olvida. Nadie le indica lo que debe hacer, a diferencia de Eneas. Este recibe mensajes en visiones o signos sobrenaturales que levantan su espiritu en los frecuentes momentos de decaimiento. Pero las dos únicas visiones oniricas de Dido referidas por el poeta tienen particular importancia. La primera, narrada por Venus, la lleva a conocer la verdad sobre la muerte de su esposo y a tomar inmediatas medidas de defensa y venganza (I, $353 \mathrm{y}$ ss.) En cuanto a la segunda, ya la analizaremos más adelante; nos limitaremos a señalar ahora que ella es decisiva para la determinación final de la joven soberana suicida.

Acaso el signo más común entre los dos agonistas sea la soledad afectiva, solitudo amoris. El breve encuentro marcará en sus vidas un instante intenso, pleno presente:

"y a la pareja de héroes le fue sólo concedido un único instante de realidad feliz, un solo instante, en que el destino de pasado de Dido pudo unirse con el destino de futuro de Eneas..."(5)

El narrador concentra en una expresión ese "olvido del mundo" por parte de los amantes: "olvidados de mejor fama"

audiit Omnipotens, oculosque ad moenia torsit regia et oblitos famae melioris amantis.

Viven su amor concentrados en ellos, regnorum immemores, como divulga la Fama, plaga veloz (...malum qua non aliud uelocius ullum;).En ese "abandono" característico de la situación amorosa, cantado por los poetas líricos del mundo en todos los tiempos. En Eneas es olvido del mandato divino y de sus reinos futuros. En Dido, olvido de su reino presente, al que empieza a descuidar, en un contraste con lo que había sido su actuación hasta ese momento como dux femina. Ha abandonado "su cuidado", esa coraza protectora que cargara la mujer de estado, se ha abandonado a las contingencias de una ilusión. 
Ese olvido es el que Júpiter le reprocha al héroe:

Quid struit? aut qua spe inimica in gente moratur nec prolem Ausoniam et Lauinia respicit arua?

Y el mandato: único, irreductible: Naviget! haec summa est,... mercurio insiste en ello al llevar su parte de mensajería divina. Halla a Eneas vestido con una túnica que le regalara Dido y armado con una espada de idéntico origen. Su imperativo es cruel y duros los apelativos con que le enrostra al héroe su "falta": uxorius, esto es, sometido a una esposa; ...heu! regni rerumque oblite tuarum: olvidado, ay! , de tu reino y de tus asuntos.

El reproche

"...Libycis teris otia terris? : consumes tus ocios en tierras de Libia; la reconvención inmisericorde:

"Si...te nulla movet tantarum gloria rerum: si no te conmueve la gloria de destinos tan grandes,

nos muestran a un Mercurio en un todo compenetrado con el Fatum Iovis exigido a Eneas y aún más: actúa como por cuenta propia, como una conciencia irritada que se propone no dejarlo en paz.

Aquí acaba el breve interludio permitido a los amantes. El héroe que enamoró a Dido con sus palabras, tanto que en ellas la reina longum bibebat amorem, ahora es parco, prefiere el silencio. Virgilio apenas sugiere lo que siente en su interior, en su "ánimo dividido". Amens, attonitus, alternans, Eneas manifiesta claramente -sin embargo-en sus acciones, que en él habrá de vencer la conciencia del deber patriótico que le espera. Por eso

...obnixus curam sub corde premebat. (IV, 332)

Más allá de lo expreso, el lector ha de advertir entre líneas su dilema afectivo, contenido en la pregunta Heu quid agat? que encabeza la descripción de su conciencia agitada por dos fuerzas y en las escuetas explicaciones que - sólo- tiene para dar a la furente enamorada:

Pro re pauca loquar... (IV, 337)

Italiam non sponte sequor. (IV, 361)

Los gozos se han transformado en duelos. Así los calificativos infelix, misera, miserrima (si bien anticipaban el destino trágico de Dido al serle aplicados en el texto desde el libro I) habrán de repetirse después, como una marca de intensificación de su dolor, unidos a otros como timens, furens, exterrita, incensa, excita, inops, dolens, trepida que va a culminar en una bellísima imagen de muerte, (contraposición total a los "laeta saecula" anunciados por Eneas al conocerla como signos de su vida terrena):

...pallida morte futura, $(I V, 644)$ 
No cabe duda que entre "laeta" y "miserrima" se abre el abismo que media dos situaciones definitivas de su vida: antes y después de Eneas; antes y después del amor conocido, vivido, y burlado luego.

La antigua solitudo laeta ya no podrá ser recuperada. En las últimas palabras de Dido percibiremos una especie de "nostalgias del bien perdido" cuando repite dos veces el adjetivo felix, indicador de su pasado, antes de Eneas, en el que no interferia el sentimiento amoroso en sus acciones de dux femina:

felix, heu nimium felix, si litora tantum

numquam Dardaniae tetigissent nostra carinae. (IV, 657)

Eneas, quizá, asumirá en su después la renuncia a sus más personales afectos como un modo habitual de vida. Es el héroe, no el gran amante. Como héroe y misión cumplida pasarán su nombre y su figura a formar parte de la Historia.

Como dice Perret:

"...c"est le conflit entre deux manieres de concevoir et de vivre l'amour, inconciliables, hélas! mais qui ont l'une et l'autre leur droit'.(6)

\section{RAZON DE AMOR}

Dos modos inconciliables de resolver el conflicto. Dido, heroina moderna, mujer al fin, ha de esgrimir en su alegato frente a la norma durísima del Fatum nada menos que una "razón de amor":

nec te noster amor... (IV, 307)

...tenet...?

Por ella, razón suficiente para una enamorada, suplica a Eneas no la abandone.

per conubia nostra, per inceptos hymenaeos,

si bene quid de te merui, fuit aut tibi quicquam

dulce meum, miserere domus labentis et istam, oro,...

Su alma apasionada se juega entera a esa única carta, razón para vivir - para norir. Hermana, en el sentimiento, de Tibulo, cuyos versos (Elegías I, III) bien podrían aplicarse, a modo de amonestación, a Eneas, a su conducta visibie tan diferente de la aconsejada por el poeta cantor de Delia:

Audeat inuito ne quis discedere Amore

aut sciat egressum se prohibente deo

Ese Amor prohibens que subordina todo a él, en la dimensión del héroe se inviertee, y es Fatum prohibens Amorem. Razones de Amor no pesan no cuentan para quien debe alcanzar la gloria -propia y de sus descendientes- en una empresa guerrera que lo alejará de la mujer amada inuito Amore y mediante alianza con un pueblo, a establecerse solamente a 
partir de su matrimonio convencional con Lavinia. Así Eneas se vio forzado antes a abandonar Troya sin Creusa; asi -se repite la historia- se hará a la mar casi a escondidas; preferirá enfrentarse con la furia de los aquilones invernales antes que faltar a la piedad. Su destino es de futuro. Dido, herida, detenida en su pasado, ha comenzado a agonizar.

\section{RAZON DE MUERTE}

Luego de agotar los recursos para retener al amado, Dido es presa de la decepción más absoluta. Una frase suya todo lo resume, lacónica, trágica:

Nusquam tuta fides.(IV, 373)

Es el momento en que decide su muerte: invoca a las divinidades de las sombras, sumida en la noche (y es más oscura aún la de sus pensamientos). La mujer fuerte, la que enfrentó las contingencias dramáticas de la muerte de Siqueo y solitaria triunfó del dolor en el cumplimiento de su función regia, ahora no se siente con fuerzas para soportar este nuevo "quedarse sola". Se dirá que está de por medio su orgullo, su fides lastimada, su honor de univira mancillado. Pero algo es indudable: Eneas ha sido el amor libremente elegido por Dido en su espléndida madurez a despecho de las normas rigurosas del Hado. Como ese amor es, en sí mismo, vída (la que volvió a latir rescatando ueteris uestigia flammae, revitalizando sus desueta corda) su ausencia no puede identificarse en ella más que con la muerte.

Su larga agonía (en el sentido etimológico: joven vida en lucha) será la sucesión de etapas en un doloroso proceso: lucha consigo misma hasta decidir el suicidio; una vez decidido, el tiempo hasta ejecutarlo; herido el cuerpo, dolorosa espera de la muerte que venga a llevar su "espiritu indignado", no es otra cosa sino el símbolo de la muerte que llega a deshora y por tanto, agonia más larga y tormentosa.

\section{LA NOCHE OSCURA}

En toda este proceso, Dido está siempre sola. Nos habiamos referido a los distintos "niveles" de su soledad. La soledad por la ausenccia futura del ser amado es la que teme enfrentarse con los fantasmas de Eneas en el palacio -sólo fantasmas, ya que ni siquiera le ha quedado a su existencia el consuelo de un pequeñuelo que acaso llevaría sus mismos rasgos:

Saltem si qua mihi de te suscepta fuisset

ante fugam subcles, si quis mihi paruolus aula

luderet Aeneas, qui te tamen ore referret, non equidem omnino capta ac deserta uiderer. (IV, 327)

Capta y deserta son los dos adjetivos usados por la propia Dido para describir su paisaje vital (o mortal) en ese momento; vencida y abandonada, desierta, como el camino que se le ofrece en sueños en una visión onírica. Haciamos referencia anteriormente a ella: constituye uno de los pasajes simbólicos claves de esta tragedia. A su soledad humana por la ausencia del 
amor perdido (Dulces exuuise, dum fata deusque sinebat, IV, 651) se le unirá algo más terrible: La solitudo deorum, soledad de los dioses. Ante ella se abre un silencio, que carga sobre sus espaldas toda la responsabilidad de lo hecho y lo por hacer. Sola ante las decisiones trascendentales, como le ha tocado siempre en suerte. No es novedad para Dido. Pero ahora, abandonada de los dioses, cae en un "pozo" de desolación, no sin antes esforzarse por salir de él pues no se rinde fácilmente. Bonifaz Nuño alude a este hecho:

"En realidad, antes aín de eer abandonada por Eneas, Dido ha sufrido un abandono mucho más amargo y decisivo: el abandono de los dioee que la han convertido en victima, y la dejaron sostenida, hasta su fin, por el solo apoyo de sus fuerzas insuficientes". (7) agonistas:

Y en ello percibe mejor este autor la diferencia que separa a los dos

"Ella...no tiene más apoyo que sus fuerzas humanas, su pasión acrecentada por el infortunio. Olvidada de los dioses, se consume sola, en cada vez más altas llamaradas inútiles.

E1, en cambio, después de haber cedido a la misma pasión, es vuelto a llamar a las esferas superiores por la intervención de los dioses, y hace caso del llamado $y$, renunciando a todo lo que de inmediato basta a ofrecerle felicidad, admite como suya la voluntad de los hados y se dispone a cumplirla". (7)

Entre los versos 450 y 477 del libro IV está contenida la descripción de la "noche oscura del alma" de la reina. Aterrada ante los Hados, invoca a la muerte. El hastio de vivir la posee ya

...taedet caeli conuexa tueri. (IV, 451)

Le hastía contemplar la bóveda del cielo; acaso porque en ese instante el cielo es sólo un hueco vacío, una concavidad lejanamente alta que le va negando toda claridad. Le repugna mirarla. Ya está en un mundo agónico que la luz abandona. Vigilia y sueño se entremezclan en una sola noche. Negras aras, negros vinos, negra sangre; voces oscuras, del interior de la tierra; voces de un muerto la reclaman. EI grito del búho, ave fatídica, funesta, acompaña ese llamado de las sombras, ferale carmen, canto funesto, lamento fúnebre. Es la soledad más grande que un alma puede sentir. Es desolación. Sola ante presagios indescriptibles: los sacrificios a los dioses devienen en signo sangriento. Ante la posibilidad de elegir, Virgilio usa el femenino sola para calificar a bubo de doble género. De ese modo Dido es aludida. Dido, la gran solitaria, furens, agitada en su pesadilla por un ferus Aeneas. En dos versos y medio el poeta pinta la imagen que de si misma tiene Dido y que se le objetiva en sueños de semivigilia. Una soledad absoluta la rodea, tal el árido paisaje único que vislumbra: ...semperque relinqui sola sibi, semper longam incomitata uidetur ire uiam et Tyrios deserta quaerere terra,

Los cinco versos siguientes presentan una comparación con dos personajes trágicos: Penteo y Orestes. Dementes, enloquecidos, ambos huyen 
perseguidos por las Furias. Términos de comparación para Lido. Iambien eslla está rodeada por las Furias y, finalmente, las concibe. Creemos que en toda la Eneida no hay un verso tan terriblemente expresivo de la deses. peración en el momento mismo en que la gran solitaria, a modo de una bacante al revés, es poseída por ella; entonces la Muerte aparece como lúcida decisión desesperada:

Ergo ubi concepit furias euicta dolore

decreuitque mori, tampus secum ipsa modumque exigit,...

"Concepit furias": no hay posibilidades de que éstas se transformen en Euménides. ¿Sombras vengadoras de qué o de quién? Dido no cree ni espera ya nada. Sólo cuenta su dolor, es la única presencia viva en su cuerpo (euicta dolore). Ahora, para Dido, sunt kacrimae rerum.

Ana es su hermana y consejera. Sin embargo, no la conoce a fondo. Fácilmente cae. en la celada y manda levantar la pira funeraria sin imagi naria tal, puesto que

...nec tantos mente furores

concipit aut grauiora timet quam morte Sychaei. (IV, 501)

Todo aparece dispuesto para su propósito de darse muerte. Sin embargo, todavia hay una última vacilación en su ánimo, una posibilidad inexplorada que acaso la salvaria para la vida. Por ejemplo, la de hacerse a la mar en una nave troyana. Es el instante último de una existencia joven y plena que no está preparada para morir. Muerte a deshora, deciamos. Cuando por la profunda herida abierta en el pecho se van escapando las últimas palpitaciones de vida, Dido aún se incorpora tres veces. Mira hacia el cielo, busca con sus ojos la luz. Ella, sumergida en su "noche oscura", entonces. gime. Esa luz ya le está nesada para siempre. Sin embargo, su juventud y sus fuerzas tardan en entregarse a las sombras. Toda la patética grandeza de la protagonista se condensa en este memorable verso:

quaesiuit caelo lucem ingemuitque reperta. $(I V, 692)$

"Buscó en el cielo la luz y, encontrándola, gimió". Expresión lírica inigualable: el símbolo de la luz -alta luz de eternidad, anhelo de absolutoy su contraste, la limitación oscura del ser humano en sus contingencias. Su Intima -y última-soledad.

\section{SOLPDADES}

Pero, tha terminado la agonia de Dido con el verso final del libro IV en el instante en que

dilapeus calor atque in uentos uita recessit?

¿Y Fneas, que debe seguir viviendo la carrera señalada por los Hados, acatada por él? 
La escena terminal de la tragedia hay que buscarla en el libro VI. Sin ella hubiera quedado un tanto opaca la imago de Eneas-hombre. Era indis pensable para que midamos los lectores en su justa dimensión los sentimientos humanos que agitaron subrepticiamente al héroe; su contención en el momento crucial, su capacidad de ofrenda de los afectos más hondos; su -podriamos decir- "automutilación" sentimental, sacrificio que lo hizo digno de fundar -a precio individualmente tal alto- una tradición luminosa, la de Roma, cabeza de naciones, centro del mundo.

\section{(Tantae molis erat Romananı condere gentem.) (I,33)}

Pcrque en las "secretas veredas entre selvas de mirtos", donde se produce el último encuentro de los amantes, es Eneas quien habla y pone a desnudo su dolor. La situación se invierte. Antes, Dido había suplicadc "por su amor"; ahora, Eneas jura por los astros, por los altos dioses del cielo y hasta -el juramento más solemne y temible- por los del Averno que "contra su voluntad" se apartó de ella.

inuitus, regina, tuo litore cessi. (VI, 460)

Inuitus Aeneas, pero sobre todo (recordemos el verso tibuliano) inuitus Amor. Todo se ha cumplido inuito Amore y Dido es ahora una sombra que se le escapa, "luna entre nublados"

obscuram, qualem primo qui surgere mense aut uidet aut uidisse putat per nubila lunam, (VI, 453)

En Eneas queda la única palabra (no hay diálogo). Y lágrimas. Tres veces el poeta se refiere al llanto del héroe:

demisit lacrimas dulcique affatus amore est (VI, 455) ...lacrimasque ciebat. (VI, 468)

$Y$, finalmente, ante la definitiva mudez de esa sombra amada, sabedor de que es la postrera vez que habrá de contemplarla, Eneas llora:

$$
\begin{aligned}
& \text {...Aeneas casu percussus iniquo } \\
& \text { prosequitur lacrimans longe... (IV, 475) }
\end{aligned}
$$

Ha de volver -falso sueño- por la puerta de marfil a la tierra, para continuar hasta el fin con su misión de conditor. Morirá cuando le llegue su hora, no forzará a los "Manes de la fábula". Pero Eneas es, también, un ser en soledad. Esta efusión en los campi lugentes lo acerca más a nuestra humanidad imperfecta. Y creemos que su herida invisible no se habrá cerrado fácilmente. Como la de Dido, que -aún apoyada en el brazo de Siqueo- aparece sin embargo viva en su pecho, reciente y en su semblante sombrio, hosco. Y nos preguntamos: ¿Hasta cuándo seguirá atormentándola el amor? ¿Siempre su ceño ha de permanecer torvo, solo fixos oculos auersa? ¿Son eternos los tormentos de amor, irreductibles a la consunción de la materia que 
los padeció en vida? Nuevamente estamos en presencia de un tópico de la literatura amorosa de todos los tiempos. "Polvo enamorado", dijo Quevedo, "Amor constante más allá de la muerte".

Una vez más aparecerá nombrada la reina sidonia en el libro XI, cuando la muerte de Palante. El caudillo tributa póstuma honra al joven y valiente guerrero vistiéndolo con una túnica recamada en oro que "en otro tiempo" habia bordado para él una laetissima Dido. La delicadeza de su sentimiento se hace patente aqui al unirse al de la pérdida del amigo. Acaso el "adiós para siempre" dado a Palante con ese gesto aluda indirectamente a su dolor secreto, el de sus soledades, guardado en su interior, subordinado a la piedad, virtud mayor del héroe.

El entramado de la Historia se entreteje con esos hechos mínimos, imperceptibles dentro del gran movimiento de los siglos, pero parte constitutiva de él. Así esta historia de amor trágico, esta contingencia (incomprensible, incomprendida para Dido; aceptada, sufrida por Eneas) era necesaria para formar las líneas de una gran "figura" universal. A partir de ese contraste entre "el querer del Hado" y "el sentimiento de las almas" limitadas por su ser de carne.

Desde el dolcr y la soledad humanas, sobre las pequeñas muertes cotidianas, se alza la vida colectiva de los pueblos, y su gloria. En el fondo de la Gran Historia siempre habrá un sacrificio, una tragedia oculta, un gran dolor o renunciamiento que hizo posible el nacimiento de algo imperecedero. Alguna criatura "despiadadamente heroica", como llama Paratore a Dido. $Y$ algún poeta como Virgilio -criatura de melancolía y penumbrasque hace de ello creación inmortal, altisimo arquetipo humano. 


\section{NOTAS}

1.- HAECKER, Teodoro: Virgilio Padre de Occidente. Col. Sol y Luna. E.P.E.S.A.; Madrid, 1945. Pág. 74.

2.- PARATORE, Ettore: Virgilio. G.C. Sansoni Edit.; Firenze, 1961. Pág. 375. La trad. es nuestra. El texto original es el siguiente:

“...il contrasto fra il volere del fato e la sentimentalitá delle anime dolorosamente legate alla loro contingenza".

3.- GUILLEMIN, A.M.: Virgilio poeta artista y pensador. Bibl. de Cult. Clasica. Edit. Paidós. Bs. As., 1968. Pág. 278.

4.- VIRGILE: Eneide - Livres I-VI; Text. Goelzer, Trad. Bellessort. Soc. Ed. Les Belles Lettres. Paris, 1970. Las citas posteriores están tomadas de la misma edición. Se indica entre paréntesis la referencia al libro y al verso correspondiente en cada caso.

5.- La frase está tomada de la novela de BROCH, Hermann: "La Muerte de Virgilio". Madrid, Alianza Editorial, 1979. Pág. 297.

6.- PERRET, J.:Optimisme et tragédie dans L'Eneide. Cap. VII en REL, T. XLV, 45o Année, 1967, Soc. D' Edit. "Les Belles Lettres", Paris, 1968, Pág. 350.-

7.- BONIFAZ NUÑO, Rubén: Tiempo y eternidad en Virgilio. Cuad. del Centro de Est. Clásicos. U.N. Autónoma de México, 1976. Pág. 98. 